Sādhanā Vol. 38, Part 5, October 2013, pp. 925-943. (C) Indian Academy of Sciences

\title{
Safety features in nuclear power plants to eliminate the need of emergency planning in public domain
}

\author{
P K VIJAYAN*, M T KAMBLE, A K NAYAK, \\ K K VAZE and R K SINHA
}

Reactor Design and Development Group, Bhabha Atomic Research Centre, Trombay, Mumbai 400 085, India

e-mail: vijayanp@barc.gov.in

\begin{abstract}
Following the Fukushima accident, the safety features of Nuclear Power Plants (NPP) are being re-examined worldwide including India to demonstrate capabilities to cope with severe accidents. In order to restore public confidence and support for nuclear power, it is felt necessary to design future NPPs with near zero impact outside the plant boundary and thus enabling elimination of emergency planning in public domain. Authors have identified a set of safety features which are needed to be incorporated in advanced reactors to achieve this goal. These features enabling prevention, termination, mitigation and containment of radioactivity for beyond design basis accidents arising from extreme natural events are essential for achieving the goal of elimination of emergency planning in public domain. Inherent safety characteristics, passive and engineered safety features to achieve these functions are discussed in this paper. Present trends and future developments in this direction are also described briefly.
\end{abstract}

Keywords. Advanced nuclear reactors; nuclear power plant accidents; emergency planning; passive features; inherent characteristics; decay heat removal.

\section{Introduction}

Nuclear power plants (NPPs) are serving the mankind for nearly six decades now and currently about 437 of them are operating in 30 countries, with installed capacity of $372 \mathrm{GWe}$, generating 2518 Giga units of electricity in 2011 which is about $12.3 \%$ of world electricity production (Nuclear Energy Institute, October 2012). They have avoided and continue to avoid release of about 8 million tones of $\mathrm{CO}_{2}$ into the atmosphere per day contributing to the prevention of global warming and climate change. While high level nuclear waste is extremely small in quantity and contained, NPPs provide electricity without any toxic release during normal operation. Presently, 64 new NPPs are under construction in 14 countries. However, three major accidents

*For correspondence 
over a period of six decades including the recent Fukushima accident have shaken the public confidence in nuclear energy and its safety record. In order to restore public confidence and support for nuclear power plants, it is felt necessary to design them with practically no impact in public domain under postulated design basis as well as beyond design basis accidents and thus eliminating the need for emergency planning in public domain. This paper is an attempt to prescribe the safety features required in such NPPs.

\section{Emergency planning in public domain-present status}

Nuclear power plants (NPPs) are designed, constructed, commissioned and operated in conformity with existing stringent nuclear safety standards implemented and monitored by regulatory bodies. These standards ensure an adequate margin of safety so that NPPs can be operated without undue radiological risks to the plant personnel or members of the public. Notwithstanding these safety standards, it is necessary to develop, as a measure of abundant caution and in conformity with international practice, emergency response plans so that any event, with a potential to result in undue radiological risk to plant personnel and public, could be handled safely.

In India, emergency planning beyond plant boundaries is considered with three distinct physical zones around NPPs with differential preparedness to respond to accidents (AERB 2000). The various barriers to release of radioactivity in case of accident are shown in figure 1.

- Exclusion zone around plant of radius $1 \mathrm{~km}$, where no habitation or productive settlements exist, with access under the complete control of the plant management.

- The sterilised zone (SZ) of radius $5 \mathrm{~km}$ around the plant, which could be quickly evacuated in response to the emergency.

- Emergency planning zone (EPZ) of $16 \mathrm{~km}$ radius for extended planning in case of severe accidental releases.

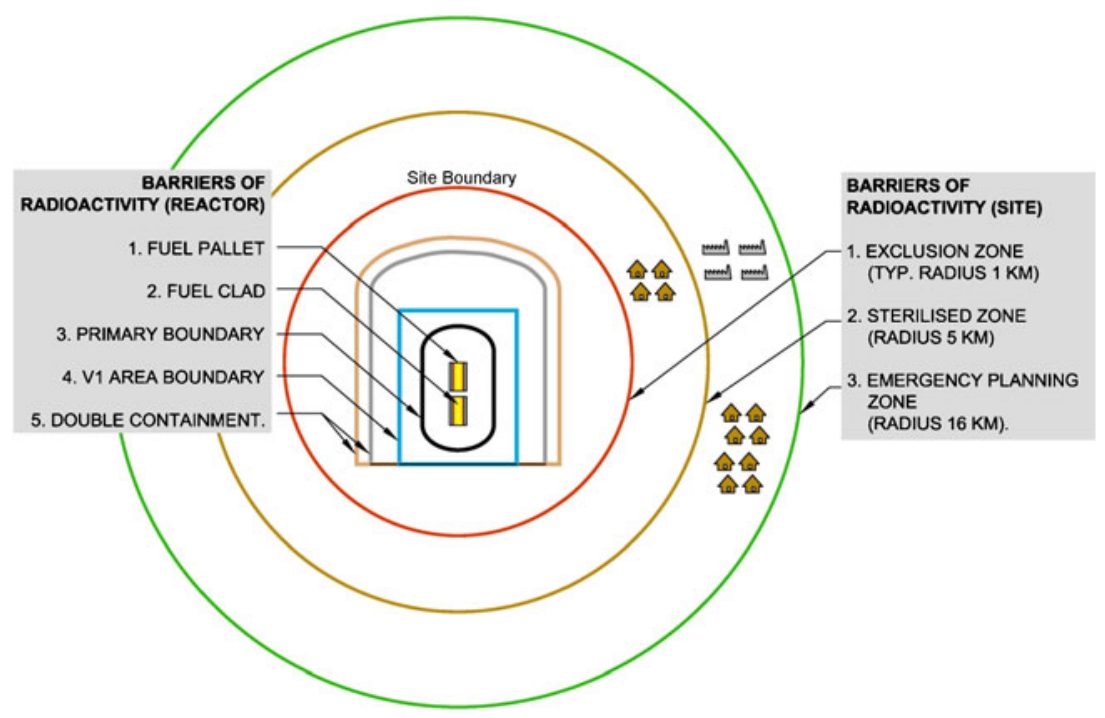

Figure 1. Radioactivity barriers and emergency planning philosophy in India. 
An accidental release of radioactivity extending beyond the plant but confined to the site boundary (exclusion zone) constitutes a site emergency. However, very low probability accidents like Loss of Coolant Accident (LOCA) plus failure of both the reactor shutdown systems and containment impairment may result into an off-site emergency releasing radioactivity in public domain. In these cases, the radiological consequences of an emergency situation originating from NPP are likely to extend beyond the site boundary and into the public domain into SZ and EPZ.

At this stage, it is desirable to review the major NPP accidents which required implementation of emergency planning measures in public domain.

\section{Brief description of major NPP accidents}

\subsection{Three Mile Island accident}

The accident and partial meltdown at the Three Mile Island (TMI) NPP Unit-2 near Middletown, Pennsylvania, on March 28, 1979, was caused by a combination of equipment malfunctions, design related problems and operator errors. TMI-2 experienced failure of main feed water pump on non-nuclear secondary side, preventing steam generators from heat removal. Following this failure, reactor was shut down as intended. However, pressure relief valve opened due to higher pressure as expected but remained stuck open for about two hours resulting in Small Break LOCA. Failure of instrumentation made operator unaware of this and series of operator actions worsened the situation, ultimately, resulting in partial core meltdown. Due to the metal-water reaction, a hydrogen 'bubble' formed in the reactor pressure vessel, leaked through the stuck open relief valve and broken rupture disk, eventually accumulating at the top of the containment building. The hydrogen-oxygen mixture had deflagration 10 hours after the onset of the accident. Fortunately, the deflagration-generated pressure spike did not exceed 2 bar (gauge pressure) and prevented containment failure. There was no other large-scale physical damage to the plant. Most of the radioactivity was contained in the plant. Nearly a million gallons of contaminated water ended up in the basement of the reactor building and in tanks in auxiliary building. This accident did not result in breach of the walls of the reactor pressure vessel and of the containment building which avoided release of radioactivity to the environment (Nuclear Regulatory Commission, USA 1980). However, public memory of the uncertainty following the meltdown was long lasting. In an atmosphere of uncertainty and anxiety, Pennsylvanian Governor after consulting Nuclear Regulatory Commission (NRC) advised for evacuation of pregnant women and pre-school age children within 5-mile radius of the plant. Amongst panic, people living near the plant also voluntarily evacuated.

Radiation exposures from the TMI accident were a small fraction of the average annual radiation exposure from natural background radiation (GPU nuclear corporation 1986). Nevertheless, this accident resulted in sweeping changes in safety philosophy in reactor design and operation, reinforcing the concepts of defense-in-depth and safety culture.

\subsection{Chernobyl accident}

On 26 April 1986, an accidental explosion during a safety test and fires at the Chernobyl NPP unit-4 in Ukraine caused the largest uncontrolled radioactivity release in the history of the civil nuclear industry. Over the next 10 days, large quantities of radioactive iodine and cesium were released into the atmosphere. Most of this material was deposited near the installation, but lighter material was carried by wind currents over Belarus, the Russian Federation and Ukraine and, to some extent, over parts of Europe. 
As an initial response, obligatory evacuation of population within a zone of $30 \mathrm{~km}$ radius was carried out. Afterwards, evacuation was extended based on spread of contamination. Restrictions on land-use were implemented and controls of radioactive contamination in foodstuffs and other produce strengthened.

About 1000 emergency workers and personnel that were on-site during the first few days of the accident received the highest doses of radiation. About 28 emergency workers died from Acute Radiation Syndrome (ARS) and two died from industrial injuries. Nineteen more died during 1987-2004 whose deaths may be related to radiation exposure (The Chernobyl Forum, 2006). However, more than 348,000 people have been resettled away from the most severely contaminated areas, some were evacuated immediately after the accident, and others were resettled several years later. The average effective doses among 530,000 recovery operation workers was 120 milli-Sieverts (mSv); among 115,000 evacuees, $30 \mathrm{mSv}$; among residents of contaminated areas, $9 \mathrm{mSv}$ (during the first two decades after the accident); and among residents of other European countries, less than $1 \mathrm{mSv}$ (in the first year after the accident). In more distant countries, doses of exposure decreased progressively in subsequent years. Since such doses are below the global average annual dose of $2.4 \mathrm{mSv}$ from natural background radiation, the radiation exposures in countries distant from Chernobyl are considered to be of little radiological and public health significance (UNDP and UNICEF 2002).

Even in countries beyond those most directly affected, Chernobyl triggered questions concerning the safety of crops, milk, food, and water; the effects of radiation exposure on different population groups; and the kind of preventive measures that were to be put in place. In many countries, the accident prompted important political discussions regarding the use of nuclear energy and national energy policies. Chernobyl also underscored the critical need for international coordination and cooperation related to environmental hazards.

\subsection{Fukushima accident}

Tohoku earthquake, which occurred on Friday, March 11, 2011, on the east coast of northern Japan, the fourth largest earthquake in recorded history, was followed by tsunami hitting the coast with a delay of 40 minutes. Along the entire east coast of Japan, at least 15,700 people were killed, 4,650 went missing, 5,300 were injured, and 131,000 were displaced (ANS 2012). The nuclear power plants (NPPs) at the Fukushima Daiichi, Fukushima Daini, Higashidori, Onagawa, and Tokai Daini were affected. Following the earthquake, all operating reactors were shutdown based on seismic instrumentation signal. The earthquake also resulted in loss of off-site power. Emergency systems were activated including diesel generators for decay heat removal and other functions. However, tsunami of $\sim 15 \mathrm{~m}$ height which hit the coast after 40 minutes, caused a loss of on-site power and emergency battery power at the Fukushima Daiichi NPP, leaving it without any emergency coolant injection capability resulting in degraded core cooling. This resulted in possible exposure of core and formation of hydrogen due to metal water reaction and subsequent pressurization of containment. The operators tried to respond with containment venting, failure of which resulted in hydrogen explosion and containment failure. The resultant damage to containment caused release of radioactive materials to the region surrounding the NPP. Following this, initially a $3 \mathrm{~km}$ radius area was evacuated and later extended to $10 \mathrm{~km}$ and subsequently to $20 \mathrm{~km}$ radius with a $30 \mathrm{~km}$ radius shelter zone. Measurable radioactive materials, mainly iodine-131 $\left({ }^{131} \mathrm{I}\right)$, cesium-134 $\left({ }^{134} \mathrm{Cs}\right)$, and cesium-137 $\left({ }^{137} \mathrm{Cs}\right)$, were identified in public water supplies as well as in certain land areas. However, after initial peaking, the concentration of these radio-nuclides reduced significantly. About 1,46,520 people were evacuated in response to the accident, though evacuation appears to be made on an ad-hoc manner. An estimated 167 
workers were exposed to more than $100 \mathrm{mSv}$ of radiation while dealing with the accident. It is estimated that as much as $1,800 \mathrm{~km}^{2}$ of land in Fukushima prefecture has now been contaminated by a cumulative radiation dose of $5 \mathrm{mSv}$ or higher per year (The National Diet of Japan 2012).

\section{NPP design features required for elimination of emergency planning in public domain}

These accidents have eroded public confidence in NPPs mainly because people living in the surrounding areas of accident affected NPPs had to abandon their homes at least temporarily causing great hardship. Thus one of the formidable post Fukushima task is to demonstrate the need to avoid emergency planning in public domain even in case of severe accidents of extremely low probability. Elimination of emergency planning essentially calls for prevention of severe accidents which is first level of defense-in-depth. In any event of severe accident, mitigation measures to control progression of accident scenario and containment of radioactivity which is next level of defense-in-depth shall ensure release of radioactivity beyond the containment boundary to be within acceptable limits. Prevention of such scenarios requires design features which would reduce Core Damage Frequency (CDF) and Large Early Release Frequency (LERF).

New design options are currently being pursued to improve the safety of future nuclear power plants. Emphasis is on simpler and easier to operate systems with passive or intrinsic characteristics which would ensure continued cooling of fuel and its containment systems. These features would enable the plant to survive potential severe accidents without fuel damage and human intervention.

The safety can be ensured in three steps. The first is to terminate fission reaction. The second is to provide assured removal of decay heat to an ultimate heat sink. The third is assured control of accident progression and mitigation of its effects. Although adequate active and passive engineered safety features are provided in existing designs, authors perceive several features to be adopted for future NPP designs to eliminate the need for emergency planning in the public domain. Some of the specific features which will support the elimination of emergency planning in public domain are discussed below.

\subsection{Inherent safety characteristics}

The features used in reactor design and material selection which can make the NPP immune to potential hazards like core meltdown or release of radioactivity are referred to as inherent safety characteristics. Often confused with passive safety, which relies on safety system components, these features rely on choice of design concept, laws of nature, properties of materials and internal stored energy with no reliance on engineering mechanisms or operator actions to prevent accidents. These features are in-built in reactor which avoid unwarranted power excursions and help to mitigate effects of accident sequence. Potential inherent hazards in a nuclear power plant include radioactive fission products and their associated decay heat, excess reactivity and its associated potential for power excursions, and energy releases due to high temperatures, high pressures and energetic chemical reactions.

Some important inherent safety characteristics of advanced reactors are:

- Negative reactivity coefficients-These provide negative reactivity feedback resulting in reduction of neutronic power or effecting shut down of the reactor in case of unwarranted power excursion or in certain accident scenarios like LOCA, which may cause rise of temperatures in core or formation of void in coolant. These are achieved through choice of fuel 
and in-core materials and design of core configuration. These are negative void coefficient of reactivity and negative temperature coefficient of reactivity.

- Low power density

- Low excess reactivity in core limiting unwarranted power rise

- Proper selection of materials-Fuel matrix with high specific heat, high thermal conductivity and high fission gas retention capacity; fuel clad materials with resistance to corrosion, no hydrogen generation by metal water reaction and oxidation; fuel coatings; elimination of potentially hazardous materials like graphite.

Inherent safety characteristics make NPP more 'forgiving' or 'tolerant'. When an inherent safety feature alone is not capable of accident prevention or mitigation beyond certain limit, safety systems, structures or components are provided in NPP to prevent, mitigate, or contain potential accidents. Although an objective in their design is to make them highly reliable, they remain in principle subject to failure (however low the probability of such failure), unlike inherent safety characteristics. Stated another way, an inherent safety feature represents conclusive, or deterministic safety, not probabilistic safety and are not subject to failure.

\subsection{Incorporation of passive safety systems in reactor design}

Passive safety systems operate based on natural physical laws such as gravity, buoyancy, etc. and derive their energy for operation from the system itself, thus they do not require external source of energy or operator actuation, bringing the reactor to safe condition by passive means. Some potential causes of failure of active systems, such as lack of human action or power failure, do not exist when passive safety is provided. Some of the examples of application of passive safety systems in future designs which can avoid occurrence of severe accident are described below.

4.2a Passive shutdown systems: Safe shut down of the reactor is important safety function which must be ensured to avoid and mitigate accidents of severe nature. Most of the shutdown systems rely on active components like instrumentation signals and power signals although made fail safe and partially passive. For shutdown of reactor under operating transients and DBAs, shutdown philosophy in line with defense-in-depth concept is widely used in almost all recent reactors, and shall remain in application in advanced reactors. This design includes at least two separate, independent, and diverse means of shutting down the reactor. At least one means of shutdown is independently capable of rendering the reactor subcritical from normal operation, and in DBAs, and maintaining the reactor subcritical by an adequate margin and with high reliability for even the most reactive conditions of the core. To improve reliability, stored energy is used in shutdown actuation. However, wired systems are vulnerable to insider threats. Passive means of reactor shutdown including instrumentation and actuation of such system will be important to combat insider threat.

Insider threat is a real possibility in these days due to the immense potential of terrorist threat, in which an insider with highly sophisticated knowledge of plant dynamics may purposefully create scenarios leading to severe accidents by compromising safety systems. In the case of malevolent acts by an insider which can be purposefully detrimental to safety of reactor and inability of plant operators to manage the events and their consequences, for a significantly long time, reactor should be capable of passively shutting down itself and maintaining coolability without regard to operator action. Examples of such systems are the density lock concept in the Process Inherent Ultimate Safety (PIUS) reactor (Boyack et al 1995) and Passive Poison 
Injection System (PPIS) in Advanced Heavy Water Reactor (AHWR) which can passively shut down the reactor even with failure of wired shutdown systems.

\subsection{Passive ultimate heat sink that cannot be lost}

Unlike conventional power plants, nuclear power plant core keeps on generating heat even after reactor shut down due to decay of fission products although in diminishing fraction of original full power of the core. Assured removal of decay heat after reactor shutdown is principal safety concern in nuclear reactors.

4.3a Passive decay heat removal: For any NPP, the main objective of safety is to provide assured removal of decay heat to an ultimate heat sink after safe shutdown of the reactor. The conventional decay heat removal systems using water or air as cooling medium are essentially active systems whose availability cannot be ensured in the event of a Fukushima type long term Station Black Out (SBO) i.e., loss of offsite, onsite and emergency power supply. Passive decay heat removal for extended periods of SBO is essential feature for ensuring safety of reactor.

Present reactor designs qualify for core coolability for finite period of time in the event of a Station Black Out (SBO) depending on design feature and regulatory requirements. The first generation of LWRs provided emergency coolant injection and decay heat removal by active means, while advanced LWR concepts use passive means to accomplish these functions. The proposed passive systems for advanced reactors generally use a pool with immersed heat exchangers. Such systems can either be on the steam generator side or on the reactor side as shown in figure 2 . They all employ natural circulation for transport of decay heat from core to pool.
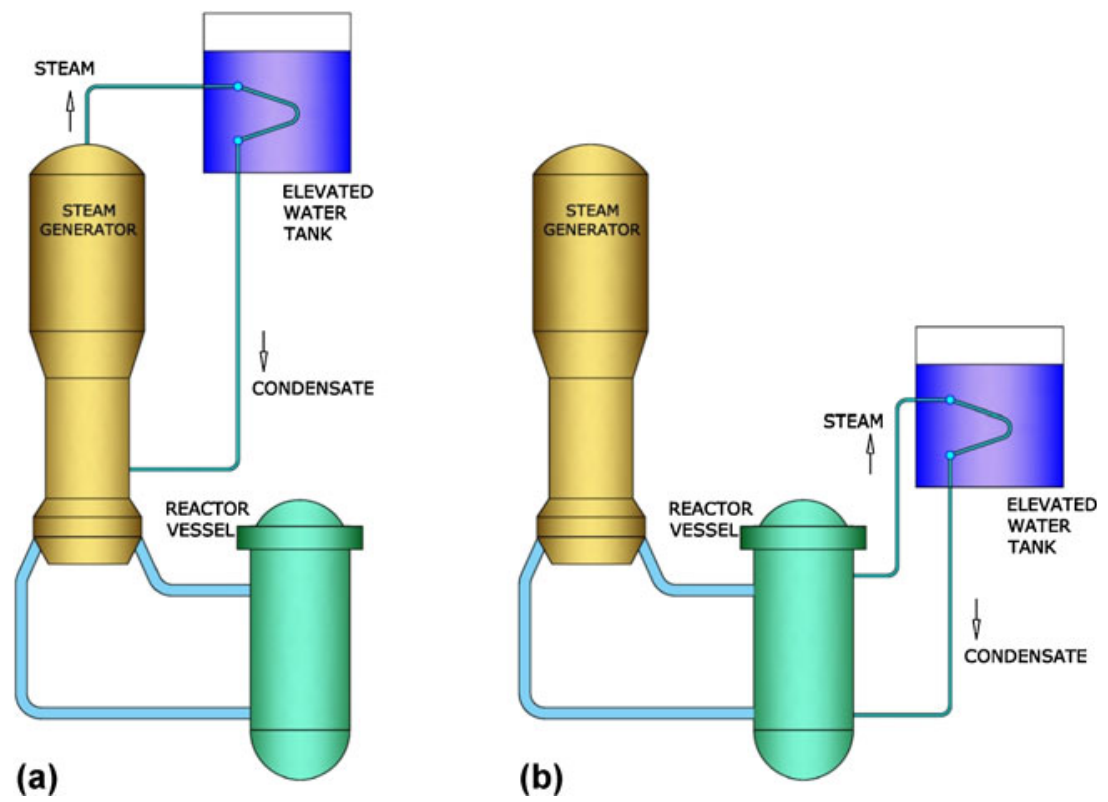

Figure 2. Limited mission time concepts for passive decay heat removal (a) natural circulation in primary circuit as well as steam generator connected to water tank, (b) natural circulation in primary circuit connected to water tank. 
However, these systems can sustain decay heat removal for finite time depending on the inventory of water in the pool making them unsuitable for extended SBOs. Another limitation is that the water can leak out in case of failure on the pool side. Therefore, ultimate heat sink which cannot be lost will be an important design feature to eliminate emergency planning in public domain. Air is an ideal infinite heat sink for decay heat removal which can ensure core coolability for infinite time as it cannot be lost unlike stored water.

Typical example is Safety Grade Decay Heat Removal System (SGDHRS) employed in Prototype Fast Breeder Reactor (PFBR) under construction at Kalpakkam, India. Figure 3 demonstrates the SGDHRS. In PFBR, main reactor vessel houses the reactor core inside a liquid sodium pool. Under reactor shutdown condition, decay heat from the core is transferred to liquid sodium pool. This heat is transferred to sodium to air heat exchanger located outside reactor building through an intermediate sodium loop. The sodium to air heat exchanger is located in a tall stack with manual dampers at bottom. Sodium flow in main vessel pool, intermediate sodium loop and air flow in stack is maintained by natural circulation. Under prolonged station black out conditions, this system can maintain temperatures of critical structures within prescribed limits without external power supply. It is a passive system except for the air dampers on the air-side (Mathews et al 2008).

The completely passive operation of the decay heat removal system requires components like valves and dampers to act by passive means. The AHWR, being developed at BARC, India employs passive valves and one way rupture disks for decay heat removal and emergency coolant injection. AHWR is a $300 \mathrm{MWe}$, vertical, pressure tube type reactor cooled by boiling light water

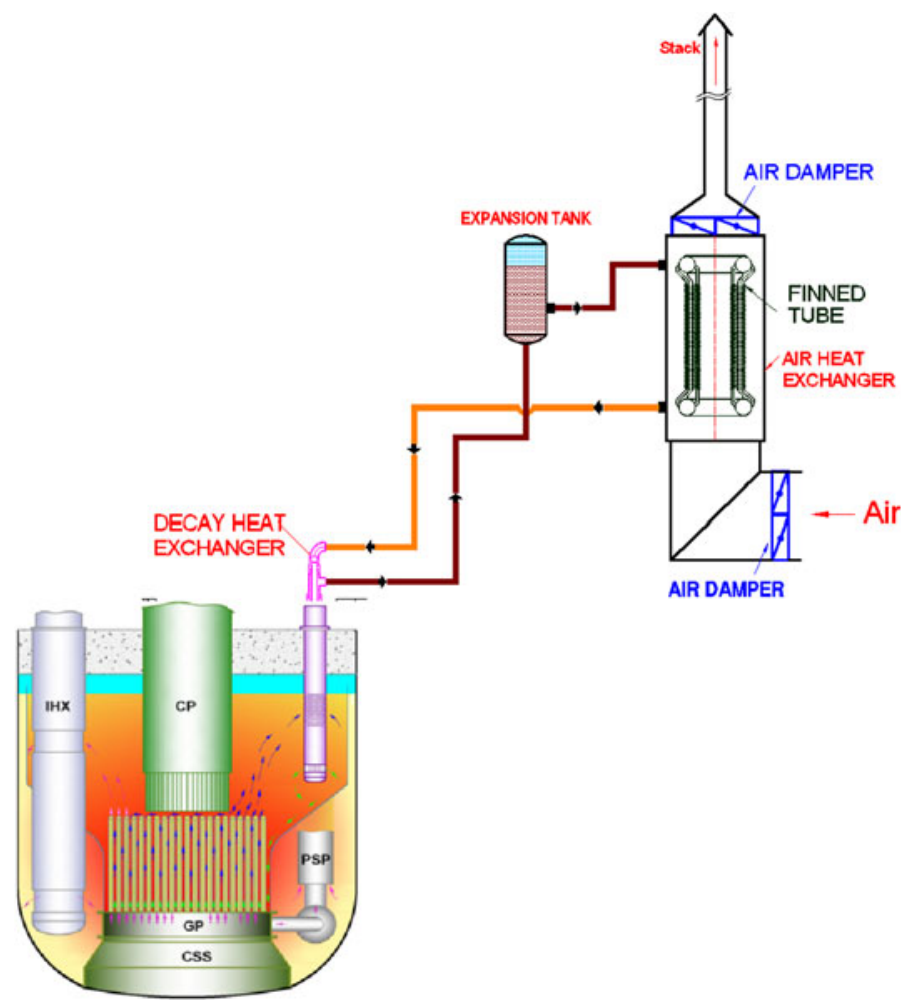

Figure 3. Safety grade decay heat removal system of PFBR. 
and moderated by heavy water aimed at large scale thorium utilization for power generation and employing advanced safety features with more reliance on passive systems and components. Figure 4 shows AHWR schematic showing its passive systems. Passive systems are incorporated for core cooling under normal operation, shutdown and accident scenarios. Additionally, AHWR adopts passive system for containment cooling following a LOCA. Besides, innovative passive safety systems have been conceptualized for several non-cooling applications such as reactor trip in case of wired shutdown system failure, containment isolation and automatic depressurization.

Passive core decay heat removal system of AHWR removes core decay heat in case of unavailability of normal heat removal path through condenser system and under station blackout condition. AHWR has a large pool of water called Gravity Driven Water Pool (GDWP) at top of the reactor building. The isolation condensers are immersed in GDWP and connected to Main Heat Transport System (MHTS) forming a natural circulation loop through passive valves called Hot Shutdown Passive Valve (HSPV). The pressure rise in MHTS actuates HSPV passively allowing natural circulation of MHT coolant rejecting decay heat to GDWP water. Thus hot shutdown condition can be maintained for prolonged periods of SBO.

With GDWP available, AHWR can withstand very long periods (exceeding 100 days) of station blackout without clad temperature rise. However, long periods of station blackout leads to containment pressure rise beyond the design pressure due to boiling of GDWP water. Under this scenario, a hard vent system becomes necessary. Hard vent system employs scrubber followed by filters, which can vent primary containment by passive means after retaining radioactive fission products and particulates in scrubber and filters. With introduction of this system, the SBO can be taken care of for very long duration.

4.3b Passive emergency core cooling system (ECCS): To mitigate the consequences of a LOCA, a passive Emergency Core Cooling System (ECCS) is provided in AHWR. ECCS injects water to Main Heat Transport system and removes heat from the fuel. It consists of passive High Pressure (HP) Injection from accumulators, passive Low Pressure (LP) Injection from GDWP

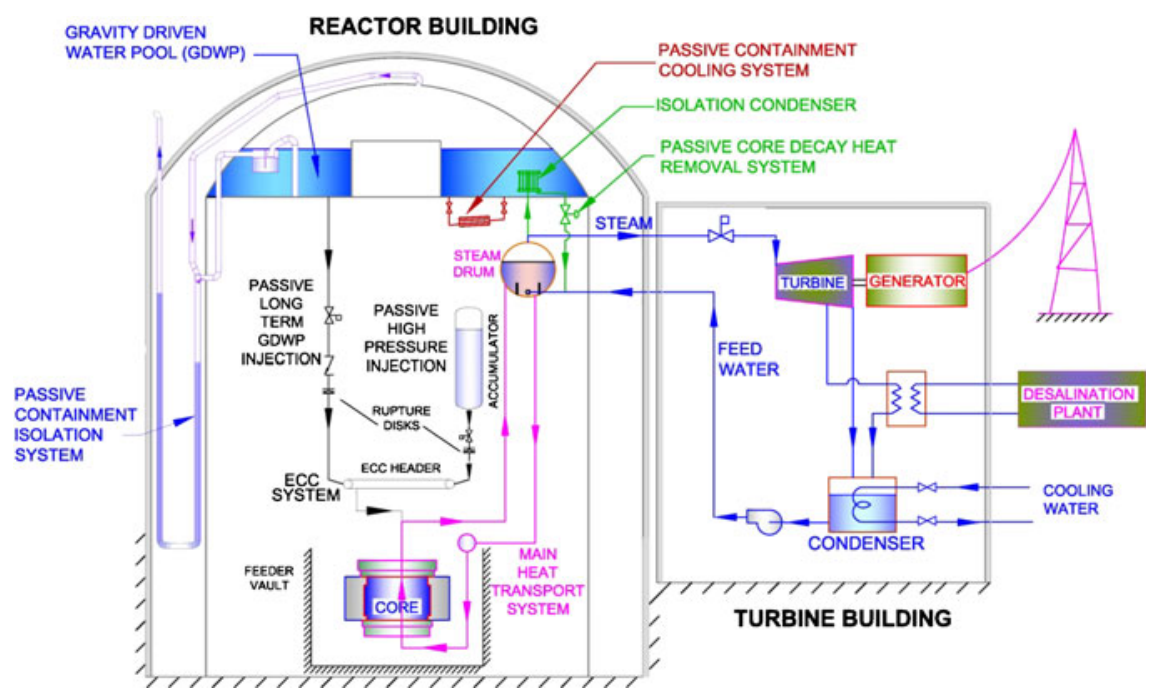

Figure 4. Schematic of AHWR showing its passive systems. 
and active Long Term re-circulation. To achieve complete passive operation, One Way Rupture Discs (OWRD) have been incorporated downstream of accumulators and GDWP. The OWRD fails at low differential pressure in the forward direction, but withstand the high differential pressure in the reverse direction. Direct injection of emergency coolant into the fuel bundle is another feature of AHWR, which ensures cooling water injection where it is most needed with least time delay.

4.3c Decay heat removal in case of failure of ECCS or after mission time of ECCS: Certain accident scenarios like failure of ECCS coupled with loss of ultimate heat sink can be dealt with by submergence of reactor vessel/primary system piping with cooling water. These concepts rely on heat being transferred from core by free convection. Pool evaporation with vapor condensation on containment walls will be source of heat removal. Vapor leaving the pool will condense on the containment walls cooled by air circulation on outer surface of containment.

In AHWR, about $6000 \mathrm{~m}^{3}$ of the GDWP water gets injected into the core following a LOCA and is adequate to provide cooling for three days. Since all the primary piping is located in V1 volume, the discharging primary coolant from the break accumulates in V1 eventually submerging the bare primary system piping providing adequate passive cooling for a long time ( $>100$ days) by the 'boil-off' mechanism. The total inventory in the MHTS and ECCS can submerge more than one-third of the tail pipe tower. An interesting feature of LOCA in AHWR is that the discharging coolant is not lost, but is passively relocated into the tail pipe tower where it continues to cool the MHTS. In other words LOCA eventually leads to ROPS (Relocation Of Passive Sink) without impairing cooling.

AHWR can ensure decay heat removal even with partial or complete loss of GDWP water due to cracks in GDWP walls in the event of an earthquake. Under these circumstances, lost GDWP water is drained in high enthalpy V1 area or in low enthalpy V2 area submerging feeder and tail pipes, which provides for core cooling for extended period (Kumar et al 2013). Figure 5 indicates feeder and tail pipe submergence levels in case of failure of GDWP structure as well as failure of water sealing at boundaries of V1 volume, primary and secondary containment. Under both conditions, the water level ensures submergence of feeder pipes providing cooling to MHTS for limited period.

Additional heat sinks around the core can also be utilised. Indian PHWRs and AHWR calandria tubes are submerged in heavy water filled calandria vessel which in turn is surrounded by calandria vault water which can act as heat sink in case of failure of cooling of primary circuit.

4.3d Passive containment cooling: In case of accidents leading to release of heat into the containment, cooling of containment is imperative to prevent pressurization of containment and to prevent escalation of accident and release of radioactivity into the atmosphere.

This is achieved passively in AHWR by incorporating a passive containment cooling system as shown in figure 4. It consists of a set of heat exchangers located underneath the GDWP. The steam-air mixture rejects heat to the GDWP water through the heat exchangers. The water circulation in the tubes is by natural circulation. GDWP with its eight compartments provides redundancy in case of leakage from one compartment due to any unforeseen reason.

In AP1000, the passive containment cooling system, provides the safety-related ultimate heat sink for the plant (Schulz 2006). It cools the containment following an accident so that design pressure is not exceeded and pressure is rapidly reduced. The steel containment vessel provides the heat transfer surface (see figure 6) that removes heat from inside the containment and transfers it to the atmosphere by the continuous, natural circulation of air. During an accident, air cooling is supplemented by water evaporation (Lee et al 2013). 


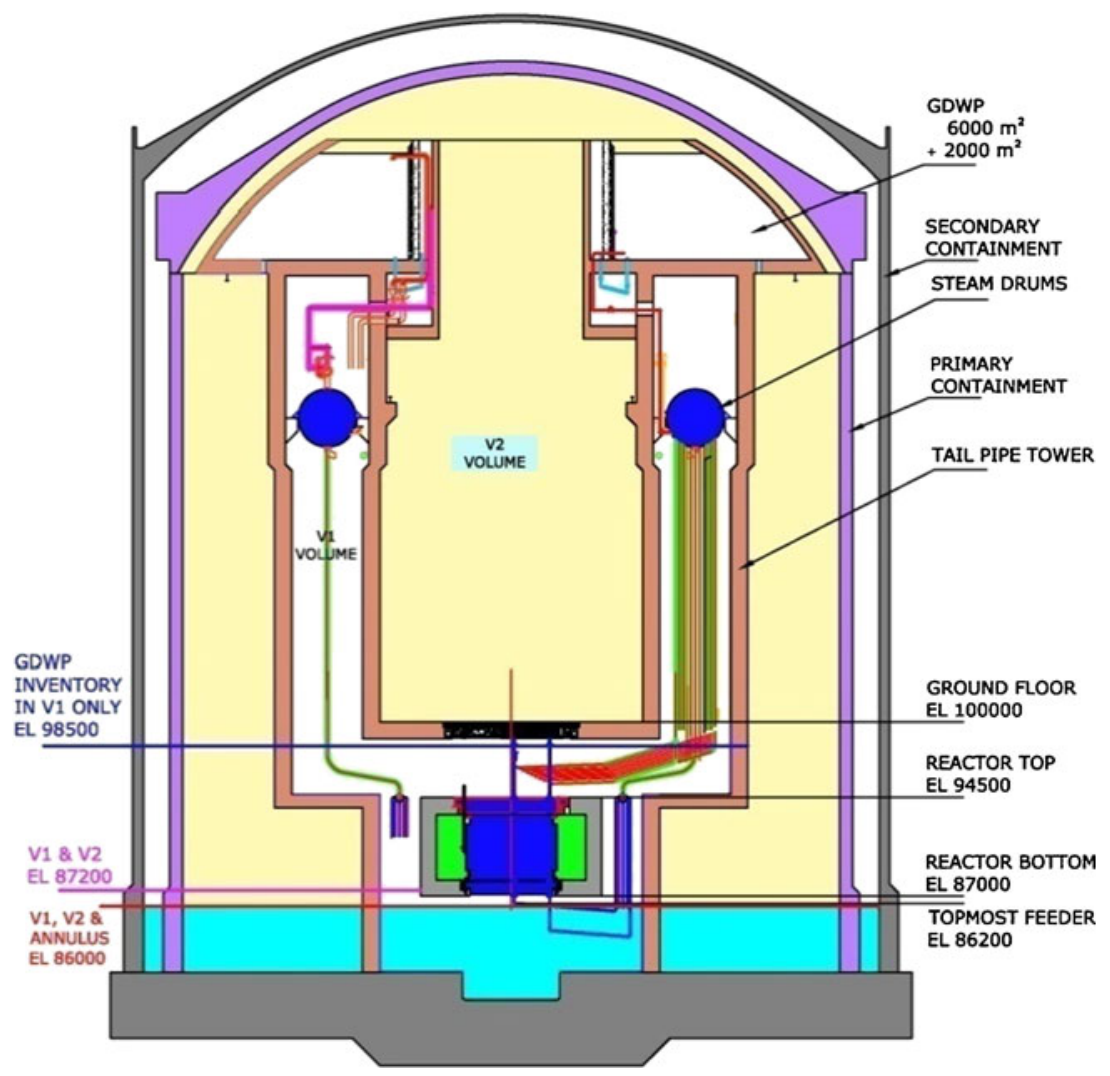

Figure 5. Feeder pipe submergence in AHWR in extreme case of failure of GDWP structure and water sealing of primary containment assures extended cooling.

\subsection{Managing decay heat in post severe accident}

Decay heat removal from uncovered cores should also be considered in case of severe accidents. In defense-in-depth philosophy, several barriers to radioactivity release like fuel, clad, primary pressure boundary and primary containment are provided. However, same barriers present difficulties in transferring decay heat from core to atmosphere, needing a balance between these two requirements. Decay heat removal from the uncovered core in case of severe accident is by radiation and convection in steam/air mixture, and conduction. The heat transfer through solid cores would require exploring new core configurations like annular fuel rod clusters and development of core components having higher cladding temperature, higher conductivity and higher heat storage capacity.

4.4a Passive core catcher design that prevents re-criticality and ensure cool down: Even though all nuclear power plant designs comply with regulatory requirements, core melt accidents can occur in case of low probability events such as extreme natural events coupled with one or more Beyond Design Basis Events (BDBE) as that happened in case of Fukushima. The purpose of a core catcher is to safely contain and cool the corium (a molten mixture of nuclear 


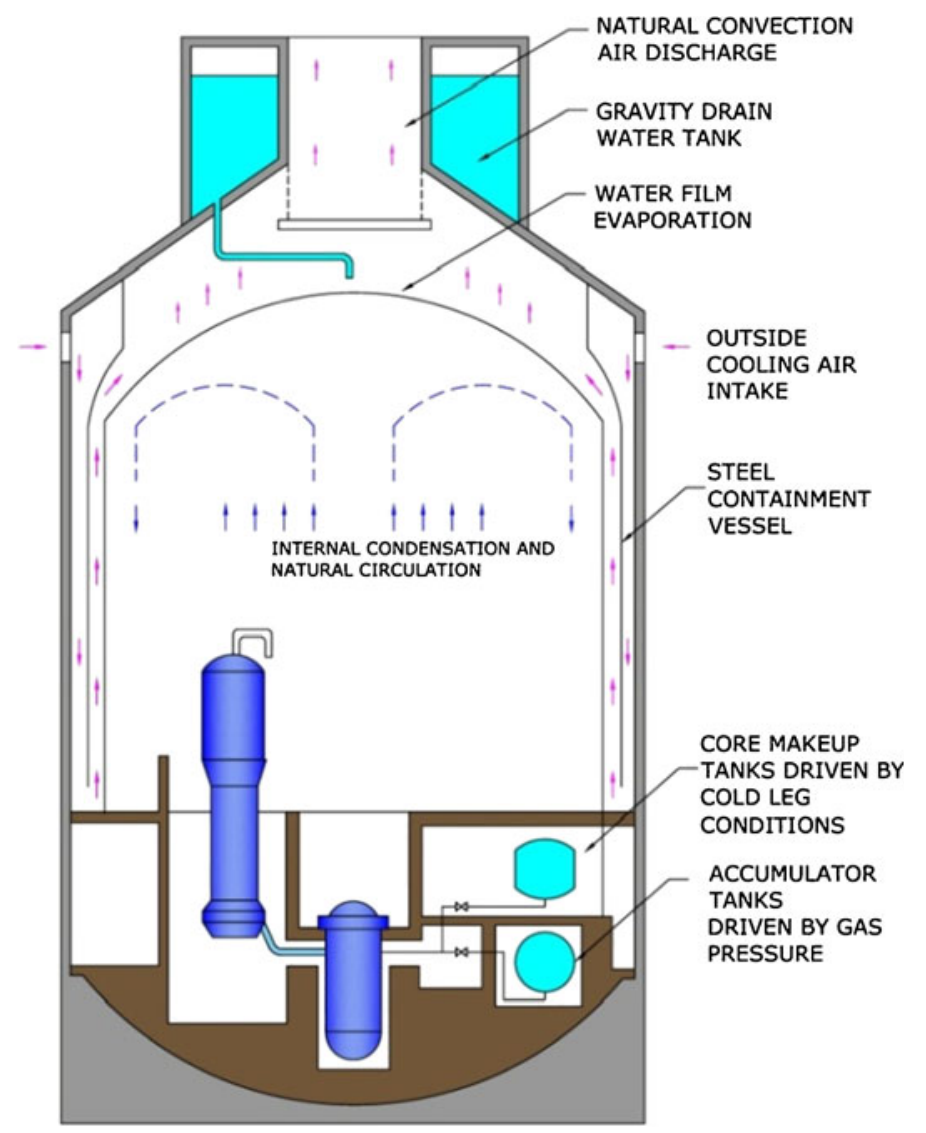

Figure 6. Passive Containment Cooling System (PCS) of AP1000.

fuel and core structural materials) and arrest the progression of core meltdown accidents (Seiler et al 2003). The basic strategies for core catcher are:

- In-vessel retention (IVR) - IVR by pre-flooding of the reactor cavity is a strategy to cool the molten core from outside the reactor vessel. This concept was adopted for Loviisa, AP600 and AP1000 (Song and Suh 2009). The heat from the molten corium in the reactor vessel is transferred via the vessel wall to the coolant outside the vessel.

- Top flooding-As per this strategy, corium released in the reactor cavity following melt down accident is cooled by flooding the reactor cavity with water. If sufficient cooling is provided, the erosion of the base concrete would stop and it would prevent a further release of fission products into the environment.

- Cooling of the debris bed in a pre-flooded cavity - In this case, the flooding of the cavity is done before the reactor vessel failure. Hence, the molten corium will be discharged into the reactor cavity filled with sub-cooled water forming a debris bed.

Several in-vessel and ex-vessel core catcher concepts have emerged over the years (Rempe et al 2004). In VVER-1000 core catcher, the molten corium will be discharged into the core catcher during meltdown. Then the corium will interact with the sacrificial materials in the core 
catcher reducing volumetric decay heat density and reducing overall temperature of the molten mass. The boiling of the water outside the core catcher will remove the decay heat from the molten core. In EPR, corium is collected in a reactor pit, conditioned with sacrificial concrete and subsequently spread onto a large surface. Water flow channel is provided along the surface of the reactor pit to cool the mixture of corium and sacrificial material. In addition, water is flooded over the mixture (Song and Suh 2009).

In case of AHWR, a core catcher has been incorporated that will prevent re-criticality and terminate the severe accident progression, retain the released radioactivity and the corium in the containment besides providing adequate cooling to the corium. Figure 7 shows a schematic of the AHWR core catcher. It consists of a layer of sacrificial concrete, a layer of high porosity concrete and provision for bottom flooding with riser tubes distributing water for cooling the corium. Cooling is provided by water flooding augmented by endothermic interaction between the corium and the sacrificial material. Normally, the downcomers draw water from GDWP. In case of unavailability of GDWP, the flooding can be carried out by fire water injection.

\subsection{Hydrogen management}

A significant amount of hydrogen is rapidly produced in the oxidation process of fuel clad zircaloy in a severe accident involving core melt. This hydrogen would then be released to the reactor containment through a pipe break or a reactor vessel rupture. Without counter measures, the hydrogen may as well prompt deflagration and detonation possibly leading to early containment failure in light water reactors as happened at Fukushima.

The hydrogen risk in a nuclear power plant may be defined as the risk of hydrogen combustion in the containment building that represents a threat to the integrity of the containment due to pressure and temperature. In case of nuclear reactor accident, the hydrogen sources are the zirconium-steam reaction, the boron carbide-steam reaction, the uranium-steam reaction, the steel-steam reaction, the late zirconium-steam reaction (re-flood of an overheated core), the relocation of zirconium-rich mixtures, the molten core-concrete interaction, the radiolytic decomposition of the primary water, and the corrosion of metallic compounds like zinc, aluminium or iron.

In DBA, the hydrogen generation is a slow process. However, in Severe Accidents, the hydrogen production is a fast process. Precise estimation of hydrogen generation rates and total quantity is therefore essential to assess hydrogen risk.

4.5a Elimination of coolant media that produces hydrogen by oxidation: Hydrogen generation in severe accidents is by metal-water reaction where source of water is coolant in the form of light or heavy water. Elimination of water as coolant can help in eliminating generation of

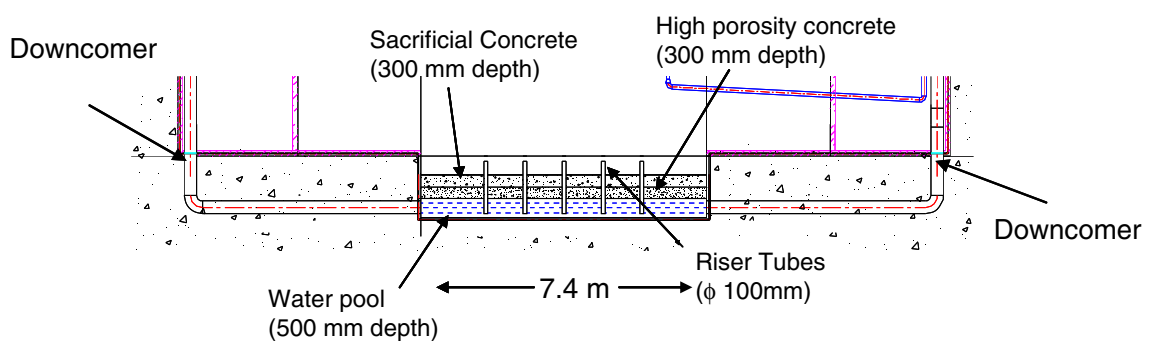

Figure 7. AHWR core catcher. 
hydrogen. Advanced reactors using high temperature molten metal/molten salts as coolant have an inherent advantage in this regard due to absence of water in direct contact with fuel clad. However, water cooled reactors would need to address this issue to avoid hydrogen risk.

4.5b Elimination of fuel clad that produces hydrogen by oxidation: A cladding material more resistant to high temperature oxidation can eliminate hydrogen risk. For future reactors operating with fast neutron spectrum, higher temperatures, coolants like sodium, lead, molten salts, etc. and higher burnups ranging up to $\sim 200 \mathrm{GWd} / \mathrm{t}$, development of new clad materials are being pursued. Several materials, such as ferritic or martensitic stainless steels, oxide dispersion strengthened (ODS) alloys, nickel based super alloys, refractory metals and materials (SiC and $\mathrm{ZrC}$ ), have been suggested as candidate fuel cladding materials. Eventually, these may find applications in water cooled reactors as well.

Silicon carbide which is being considered as fuel clad material has several major advantages over Zr-based clad material. These include:

- Lower absorption of thermal neutrons.

- Little corrosion and no hydrogen pickup during normal operation, thus enabling a major increase in fuel life and energy content.

- Strength retention and low corrosion rate at elevated temperatures.

- Much slower degradation in a severe accident scenario; no meltdown, low corrosion rate, less/no hydrogen generation.

Though SiC fibres start off at a somewhat lower strength than Zr-based cladding, they retain their strength at very high temperatures. This provides a significant advantage in maintaining coolable fuel geometry during beyond design basis accidents. An additional advantage is the resistance to steam and air oxidation. Testing has shown that while $\mathrm{Zr}$ cladding has up to $17 \%$ oxidation after $400 \mathrm{~s}$ in $1200{ }^{\circ} \mathrm{C}$ steam, SiC samples have negligible mass loss even after $800 \mathrm{~s}$ at $1200{ }^{\circ} \mathrm{C}$. Also, since $\mathrm{SiC}$ is a ceramic, it will not balloon as $\mathrm{Zr}$ alloy cladding until it reaches its failure point. The failure temperature for $\mathrm{SiC}$ cladding is estimated to be greater than $2000{ }^{\circ} \mathrm{C}$. Equally important in nuclear applications is the favourable response of $\mathrm{SiC}$ to radiation fields. While thermal conductivity decreases after irradiation, it remains comparable to zirconium clad without significant decrease in strength (Hallstadius et al 2012).

4.5c Fast recombination of hydrogen: Passive Autocatalytic Recombiner (PAR) has emerged as a hydrogen control device in modern NPPs. PARs are self-starting, self-feeding and do not require power for operation. They instead use a platinum and/or palladium catalyst to recombine hydrogen and oxygen gases into water vapor upon contact with the catalyst. The heat produced during recombination process creates strong buoyancy effects which increase the influx of surrounding gases to the PAR inlet. These natural convective flow currents tend to promote mixing of combustible gases preventing formation of hydrogen pockets in the reactor containment.

The chemical reaction between hydrogen and oxygen to form water is a strongly exothermic reaction $\left[\mathrm{H}_{2}+(1 / 2) \mathrm{O}_{2} \rightarrow \mathrm{H}_{2} \mathrm{O}+238 \mathrm{~kJ} / \mathrm{mol}\right]$ that starts only after overcoming a high activation energy. The activation energy can be significantly reduced by the use of catalysts (platinum, palladium), so that the reaction can start at low temperatures without propagation to the surrounding atmosphere. The mechanism for catalytic oxidation of hydrogen on metals is that of Langmuir-Hinchelwood with two steps that are the diffusion of the reactants, and the reaction 
of absorbed reactants on the catalyst. A catalytic recombiner comes into action spontaneously as soon as the hydrogen concentration begins to increase in the reactor building atmosphere (Park et al 2011). Catalytic recombiners can be used currently to protect nuclear power plants against hydrogen risk.

At the moment, the catalytic recombiners are recognized by many nuclear safety authorities and adopted by nuclear power plant utilities all over the world. PARs are used in NPPs in Europe, Canada and USA. Following the Fukushima accident, a decision to back-fit all Indian NPPs with PAR was taken and is being implemented.

4.5d Pre-inerting of containment: Another concept for the hydrogen hazard mitigation in existing nuclear power plants is pre-inerting which is employed in boiling water reactors in Germany, Japan, USA and Sweden (Bachellerie et al 2003). Purging management is used in many US BWRs which utilize nitrogen inerting as the primary defense against hydrogen ignition (Dallman et al 1988).

4.5e Controlled release of hydrogen/hardened vent: Severe accidents can produce large quantities of hydrogen in short time beyond the recombination capabilities of PARs resulting in serious hydrogen risk. Timely venting of the containment is essential for hydrogen management as well as to avoid containment pressurization. A 'hardened vent' is a separate vent pipe designed to withstand higher loads during an accident and routed to an elevated point outside the reactor building. These vents are designed to withstand the pressure and temperature of the steam generated early in an accident. The vents must also withstand possible fires and small explosions if they are used to release hydrogen later in an accident. A hardened vent system usually incorporates a set of isolation valves designed to prevent an unintended release of fission products into the environment. Various reactors in operation include features that allow operators to vent gases from the primary containment in an emergency. Hard vents have been installed in many Mark I containments in US, following NRC recommendation of 'Installation of hardened Wetwell vent' in 1989. However, most designs rely on remote/manual electrical operation.

Importance of such hard vent can be established looking at the inability of venting and subsequent hydrogen explosion at Fukushima. Fukushima Dai-ichi Units 1, 2, 3, and 4 required actuation of active valves and instrumentation for venting reactor building to stack which could not be achieved due to loss of AC power. The operator's inability to vent the containment most likely resulted in the leakage of hydrogen gas into the reactor building, precipitating explosions that blew away the containment roof. Venting systems are presently designed with active components like instrumentation, AC power and control logics to address such scenarios. Alternatively, a reliable venting capability can be provided through a passive containment venting design, such as rupture disks with independent isolation valves. Such passive vents provide fail-safe containment pressure relief with no operator action or power supplies.

Significant reduction in the release of radioactive airborne contamination can be achieved by the scrubbing action of pool water along with filters to arrest particulates discharging to atmosphere. Many European countries like France, Germany and Sweden use high-capacity filter systems, intended to limit the contamination of the environment to 0.1 percent of the reactor core inventory of radioactive material in the event of a severe accident (Leyse 2012).

Hardened vents with passive features and high capacity filtering will be the way ahead for NPPs for ultimate mitigation of hydrogen risk and for protection of public from radioactivity release. Following the Fukushima accident, a decision to back-fit all Indian NPPs with hard vent 
was taken and is being implemented. AHWR will also employ PAR and hardened vents for hydrogen mitigation.

\subsection{Fire proof containment and physical protection}

Following 9/11 terrorist incident, several measures were identified for physical protection and fire safety. With present scenario on security of nuclear installations, perhaps the most important aspect of gaining public acceptance is addressing the need for enhanced security through nuclear safety as design objective.

A terrorist attack is now being considered as Design Basis Threat (DBT) with objective assessment of demographic security needs and regulatory framework for safety against such external manmade threats is being continuously modified. However, apart from security protocols, NPPs need to incorporate several design features to ensure that no unacceptable radiological impact outside the plant boundary happens even with such attack.

A robust containment structure to protect internal systems against external threats is important aspect in this regard. Such containment shall be capable of safety against missile, aircraft impact, sabotage and fire for extended periods.

These threats can be categorized under following:

(i) External threat-physical, cyber, biochemical, and other terrorist threats, 26/11 Mumbai type multiple coordinated attack, 9/11 type aircraft/missile/explosive attack, theft or diversion of nuclear material.

(ii) Internal threat-attack from several persons employed at the facility possibly with a sophisticated knowledge of facility operations.

Even before the recent attacks, nuclear power plants were designed to protect public health and safety. The plants achieved this through their robust containment buildings, redundant safety systems, highly trained operators and maintenance staff, stringent security plans, and armed security personnel. In future reactors, continuous evaluation and improvement of safety and security philosophy will be essential as these threats are inherently dynamic and intelligence is often limited to predict the threat.

However, best safety against such threats lies in design of the NPP. Passive and inherent safety features and effective implementation of safety philosophy in future reactors can provide large part of the solution.

It is clear that in 9/11 type attacks, containment will provide most important physical barrier for mitigation. For example, in EPR Finland design, the reactor building as well as the surrounding auxiliary buildings housing safety related equipment are structurally strengthened to the extent needed for surviving the impact of a large commercial aircraft. Some design measures, provided to deal with specific external events, call for additional protective features in plant layout and design. In EPR and SWR 1000, for example, aircraft crash protection measures have been implemented through attention being paid to plant layout, low vertical profile of containment, and additional robustness of protective external structures (IAEA-TECDOC-1487 2006).

\section{Proposed future development}

Few development aspects to achieve the goal of elimination of emergency planning are briefly listed below. 


\subsection{Station blackout}

Extended SBO with loss of infrastructure in and around NPP will be a design issue for future reactors. Developing systems in NPPs which can rely on providing cooling capabilities for infinite time in case of extreme natural events with the help of ultimate heat sink that cannot be lost would be essential. The following mitigation capabilities are required for extended SBO situations:

- Maintaining highly reliable onsite electric power systems/instrumentation.

- Additional sources of coolant water for the reactor and steam generators.

- Passive methods of depressurization of primary system and feed water system.

- Passive methods to cool the reactor core and minimize releases of radioactive materials from containment.

\subsection{Hydrogen management}

Assessing and addressing hydrogen risk of the plant will require study of advanced NPP designs and their characteristics, selection of accident sequences, assessment of the hydrogen sources as well as the steam sources, follow-up and modelling of the hydrogen/oxygen/inert gas distribution, and evaluation of the hydrogen combustion risk based on factors like response of venting and inerting systems. Scrubbing or filtration systems would be needed to reduce release of activity in case of venting. Development of effective PAR systems can greatly reduce hydrogen risk, however analyses of different accident progression scenarios is required.

\subsection{Fuel cladding development}

There are many practical issues associated with introducing $\mathrm{SiC}$ based fuel cladding today. These include manufacturing technology, large-scale manufacturing costs, fundamental understanding of the composite technology, and licensing. Though monolithic SiC tubes are very strong, they are brittle. A cost-effective large-scale manufacturing technique for $\mathrm{SiC}$ precursors, fibres and composite structures is also challenging. Performing the testing and in-reactor verification required to assure regulators and commercial operators of the safety and efficacy of the SiC clad.

\subsection{Containment design}

The ability of the containment system to withstand loads associated with severe accidents need to be assessed like various heat sources, including residual heat, metal-water reactions, combustion of gases, gaseous release control, pressure and temperature variations and effects of the accident on the integrity and functionality of internal structures.

Containments may provide ultimate barrier to terrorist attacks. The advancements in civil design, layout optimization and incorporation of inherent and passive safety systems with redundant and diverse service trains would be important.

\subsection{Core catcher design}

Major core catcher design challenges arise from the fact that response of core catcher is unique to various accident scenarios and reactor core design. Effective core catcher design will involve understanding of various material and neutronic properties with different material combinations apart from understanding the nature of corium mix. To evaluate criticality in the core catcher, the 
conditions of the corium and the core catcher after accident sequence must be determined. Various physical phenomenon like changes in the corium mass and material composition, porosity due to water vapor, layer separation, shape of corium mix, impact on structural and containment materials in contact with corium and their combined effect on criticality analysis would be important features of future research in core meltdown accidents.

\section{Concluding remarks}

Accident prevention is the main driving force for safety enhancements in advanced NPP designs. Several design innovations are aimed towards bringing down CDF and LERF to an extent that makes the plant less vulnerable to extreme external events and malevolent acts. Preventing accidents, termination of accident sequence, mitigating the effects of accidents and containment of radioactivity is essential for achieving the goal of elimination of emergency planning in public domain.

Typical approaches to achieve these goals would be robust NPP design with intrinsic safety features encompassing neutronics, thermal hydraulics, materials and structures, inherent and passive safety with redundancy, diversity, physical separation in reactor shutdown and decay heat removal. Development of passive ultimate heat sink that cannot be lost, passive core catcher design that prevents re-criticality and ensure cool down, elimination of hydrogen risk, fire proof containment and physical protection as well as passive shutdown and passive controls to overcome insider threat will be essential.

An integrated design approach for NPPs to avoid release of radioactivity outside the containment in severe accidents involving core meltdown would be the key to eliminate emergency planning in public domain.

\section{References}

ANS (2012) Fukushima Daiichi: American Nuclear Society (ANS) Committee Report

AERB (2000) Preparedness of the operating organisation for handling emergencies at Nuclear Power Plants, Safety Guide No. AERB/SG/O-6, Atomic Energy Regulatory Board (AERB), India

Bachellerie E, Arnould F, Auglaire M, de Boeck B, Braillard O, Eckardt B, Ferroni F and Moffett R (2003) Generic approach for designing and implementing a passive autocatalytic recombiner PAR-system in nuclear power plant containments. Nuclear Engineering and Design 221: 151-165

Boyack B E, Steiner J L, Harmony S C, Stumpf H J and Lime J F (1995) Reactor scram events in the updated PIUS 600 Advanced reactor design, LA-UR-94-4403, Conf-950828, National Heat Transfer Conference, Portland, Oregon, August 5-9

Dallman R J, Hulman L G and Kudrick John (1988) Filtered venting considerations in the United States, CSNI Specialists Meeting on Filtered Vented Containment Systems, Paris France, p. 5, May 17-18

GPU nuclear corporation (1986) Radiation and health effects, A report on the TMI-2 accident and related health studies

Hallstadius L, Johnson Steven and Lahoda Ed (2012) Cladding for high performance fuel. Progress in Nuclear Energy 57: 71-76

IAEA-TECDOC-1487 (2006) Advanced Nuclear Plant Design Options to Cope with External Events

Kumar M, Kulkarni P P, Kamble M T, Nayak A K, Vijayan P K and Vaze K K (2013) AHWR Analysis for the Post-Fukushima Scenarios, accepted for 22nd National and 11th International ISHMT-ASME Heat and Mass Transfer Conference, organized by IIT Kharagpur, India

Lee D-S, Liu M-L, Hung T-C, Tsai C-H and Chen Y-T (2013) Optimal structural analysis with associated passive heat removal for AP1000 shield building. Applied Thermal Engineering 50: 207-216 
Leyse M (2012) Post-Fukushima Hardened Vents with High-Capacity Filters for BWR Mark Is and Mark IIs, A Project Completed for NRDC

Mathews T S, Ramakrishnan M, Parthasarathy U, John Arul A and Senthil Kumar C (2008) Functional reliability analysis of safety grade decay heat removal system of Indian 500 MWe PFBR. Nuclear Engineering and Design 238: 2369-2376

National Diet of Japan (2012) The official report of The Fukushima nuclear accident independent investigation commission

Nuclear Energy Institute (2012) World Nuclear Generation and Capacity

Nuclear Regulatory Commission, USA (1980) Three Mile Island - A report to the commissioners and to the public - Volume I \& II

Park J-W, Koh B-R and Suh K Y (2011) Demonstrative testing of honeycomb passive autocatalytic recombiner for nuclear power plant. Nuclear Engineering and Design 241: 4280-4288

Rempe J L, Knudson D L, Condie K G, Suh K Y, Cheung F B and Kim S B (2004) Conceptual design of an in-vessel core catcher. Nuclear Engineering and Design 230: 311-325

Schulz T L (2006) Westinghouse AP1000 advanced passive plant. Nuclear Engineering and Design 236: $1547-1557$

Seiler J-M, Latrobe A, Sehgal B R, Alsmeyer H, Kymäläinen O, Turland B, Grange J L, Fischer M, Azarian G, Bürger M, Cirauqui C J and Zurita A (2003) Analysis of corium recovery concepts by the EUROCORE group. Nuclear Engineering and Design 221: 119-136

Song J H and Suh N D (2009) An evolution of molten core cooling strategies. Nuclear Engineering and Design 239: 1338-1344

The Chernobyl Forum: 2003-2005 (2006) Chernobyl's Legacy: Health, Environmental and SocioEconomic Impacts and Recommendations to the Governments of Belarus, the Russian Federation and Ukraine, Printed by IAEA Division of Public Information: D. Kinley III (Editor), 2nd Revised version

UNDP and UNICEF (2002) The Human Consequences of the Chernobyl Nuclear Accident - A Strategy for Recovery, A Report by UNDP and UNICEF with the support of UN-OCHA and WHO 